\title{
O PAPEL DO JUIZ NO PROCESSO CIVIL MODERNO O JUIZ E A EFETIVIDADE DO PROCESSO
}

\author{
Rachel Lopes Queiroz Chacur
}

Docente do Curso de Direito - UNOESTE. E-mail: rachel@unoeste.br

\section{RESUMO}

A finalidade dessa temática é apresentar os problemas técnicos do sistema processual e éticos da figura do juiz, para o aprimoramento da prestação e efetividade da tutela jurisdicional. A História do Direito Romano, desde os tempos de Justiniano ${ }^{1}$, relata o problema da efetividade da tutela jurisdicional ${ }^{2}$, sempre atrelada à questão do Acesso à Justiça e a sua morosidade. No entanto a efetividade da tutela jurisdicional, em sua complexidade, além desse princípio constitucional, acentua o formalismo exacerbado, a ineficiência da organização judiciária, o sistema processuallegal, os fatores sócio-econômicos e a formação profissional e ética dos operadores do direito, atemporizada ao contexto social. Nas décadas de 80 e 90, as alterações no sistema processual civil brasileiro contribuíram para a evolução técnico-científica e a efetividade do processo. Contudo, em virtude das colaborações e abordagens nos mais variados ramos das Ciências, constata-se que a problemática da efetividade da tutela jurisdicional está além de premissas legalistas e sistemáticas. Dentre as principais críticas dos doutrinadores, está o paradoxo do instrumento justo (celeridade versus estabilidade) e a formação do juiz no Estado Constitucional e Democrático de Direito ${ }^{3}$.

Palavras-chave: Processo Civil - Juiz - Código de Processo Civil

\section{INTRODUÇÃO}

A doutrina pátria e estrangeira trata, com imprecisão terminológica, o conceito da efetividade, pois é um termo polissemântico e aberto - efetivar "s.m. tornar efetivo, levar a efeito, realizar" ou efetivo "adj. Que existe realmente, real, verdadeiro, positivo" ${ }^{4}$; ou mesmo utilizam a expressão efetividade do processo delimitando ao remoto caráter meramente técnicoinstrumental, ao invés da precisa conceituação efetividade da tutela jurisdicional.

A efetividade da tutela jurisdicional é garantia constitucional, que assegura a adequada tutela de direito prestada pelo protetivo Estado-Juiz ${ }^{5}$, decorrendo o princípio da

\footnotetext{
${ }^{1}$ CALAMANDREI, Piero. Eles, os Juízes vistos por um advogado. Tradução Eduardo Brandão, Martins Fontes, p- 159/160, São Paulo, 1998. “ Desde os tempos de Justiniano, quando se concebiam os meios processuais para impedir que os litígios se tornassem paene immortales, o processo era imaginado como um organismo vivo, que nasce, cresce e, por fim, se extingue por morte natural com o julgado, quando não intervém, para fazê-lo morrer antes, aquela espécie de infaticídio processual que é a conciliação, ou aquela anemia perniciosa que é a perempção.

Mas a personificação do processo concebido como uma criatura viva, eu nunca tinha percebido tão natural e elegante como na linguagem de um velho camponês toscano, que certa vez me procurou para que o defendesse em apelação numa causa que, na simples fase de primeira instância, já durava seis anos."

${ }^{2}$ AZEVEDO, Luiz Carlos de Azevedo; TUCCI, José Rogério Cruz.

${ }^{3}$ GOMES, Luiz Flávio. A dimensão da Magistratura no Estado Constitucionals e Democrático de Direito. Revista dos Tribunais, 1997, p-117." Está definitivamente afastada a doutrina de Kelsen no sentido de que a Constituição abre espaço dentro do qual transita o legislador, enquanto este abre novo espaço por onde caminha o juiz. O Estado Constitucional de Direito, muito diferentemente, permite o confronto direito entre a sentença e a Constituição, é dizer, todo ato judicial é (deve ser) um ato de controle de constitucionalidade da lei".

${ }^{4}$ HOAISS, Koogan. Enciclopédia e Dicionário Digital. CDRom, Editora Delta, 1999.

${ }^{5}$ GRECO, Leonardo. A Execução e a Efetividade do Processo. Revista de Processo 94, ano 24, abril/junho, Editora Revista dos Tribunais, ano 1999, p34 e 35 . "Essa efetividade, consagrada no próprio Texto Constitucional (art.5, parágrafo 19), espraia os seus efeitos por todos os ramos do Direito,
} 
inafastabilidade das decisões judiciais e do resultado prático do processo. ${ }^{6}$ Vale ressaltar-se que alguns doutrinadores atrelam o vocábulo efetividade, verbo latino efficere, à eficácia da lei processual ${ }^{7}$. Também o conceito de efetividade corresponde à eficácia do sistema processual, acrescida da aptidão para gerar efeitos no plano fático da sociedade ${ }^{8}$. Para MARCACINI ${ }^{9}$, a efetividade do processo "consiste na aptidão deste para realizar praticamente os fins a que se propõe", sempre objetivando alcançar as finalidades do processo, como a pacificação social e o bem comum, fundamentados nas garantias e nos princípios básicos constitucionais. Apresenta Barbosa Moreira ${ }^{10}$ um "programa básico em prol da efetividade", em suma a simbiose do processo como instrumento à tutelar adequadamente aos direitos garantidos no ordenamento jurídico, com pouco dispêndio de tempo e útil, para alcançar o maior resultado almejado pelas partes $^{11}$.

A efetividade da tutela jurisdicional é o equilíbrio entre justiça, acesso, estabilidade e celeridade. ${ }^{12}$

particularmente por aqueles que regulam as relações jurídicas entre o Estado e os particulares, que se despem do anterior perfil marcantemente autoritário e se humanizam para se tornarem instrumentos do libre desenvolvimento da personalidade. Transparência, participação democrática, presunção de inocência, devido processo legal, contraditório, publicidade, intimidade, ampla defesa, são algumas das expressões que se tornaram populares no nosso tempo, como respresentativas de regras mínimas de convivência social, essenciais para que todos os cidadãos vejam respeitada pelos demais e pelo próprio Estado a sua dignidade humana. A progressiva clarificação do conteúdo concreto de muitos desses conceitos e valores humanos, que está muito longe de ter-se completado, particularmente em nosso país, de atávica tradição autoritária e paternalista, fez-se acompanhar de um desgastante processo crítico de aferição à eficácia operativa das normas jurídicas, através de critérios políticos, econômicos, sociológicos e estatísticos que, não obstante muitas vezes polêmicos, definem a busca da construção de uma nova ordem jurídica que, respeitando o pluralismo inerente à sociedade moderna, dê a todos condições iguais de encontrar a própria felicidade e de exercer amplamente a própria liberdade sem pôr em risco a felicidade e a liberdade dos demais. Essa revisão crítica da operatividade das instituições jurídico-políticos e das normas jurídicas assecuratórias dos direitos fundamentais certamente seria extremamente positiva para o aprimoramento da convivência pacífica de todos os cidadãos e de todos os povos, se paradoxalmente, a sociedade moderna, em decorrência da economia de escala e do frenético desenvolvimento tecnológico, não tivesse potencializado as necessidades humanas, progressivamente modificado a aptidão dos bens materiais de satisfazê-las, massificando as relações econômicas e sociais e os conflitos delas decorrentes, reduzindo o Estado provedor do bem comum à completa incapacidade de atender a todas as demandas e a proteger concretamente todas as situações de fato teoricamente agasalhadas pelo Direito."

${ }^{6}$ MARINONI, Luiz Guilherme. A efetividade da do processo e Tutela de Urgência. Editora Sergio Antonio Fabris, p- 66, Porto Alegre, 1994. “ Ora, se o Estado tem o dever de prestas a "devida tutela jurisdicional", entendida esta como a tutela apta a tornar efetivo o direito material, o cidadão tem o direito à "adequada tutela jurisdicional", que é elemento indissociável do due process of law. Direito à adequada tutela jurisdicional quer dizer direito a um processo efetivo, próprio às peculiaridades da pretensão de direito material de que se diz titular aquele que busca a tutela jurisdicional."

${ }^{7}$ Op. cit. 3. Eficácia: sf. Qualidade daquilo que produz o efeito que se espera.

${ }^{8}$ ARAGÃO, Egas Dirceu Moniz de. Efetividade do Processo de Execução, in O Processo de Execução - estudos em homenagem ao Professor Alcides de Mendonça Lima (org. Araken de Assis e Carlos Alberto Álvaro de Oliveira), Porto Alegre, Sérgio Antonio Fabris Editor, 1995, p - 127. “ o vocábulo "efetividade" enraíza no verbo latino efficere, que corresponde a produzir, realizar, e significa "qualidade do que está efetivo: estado ativo de fato".

9 MARCACINI, Augusto Tavares Rosa. Estudo sobre a efetividade do processo. Tese apresentada ao Departamento de Direito Processual da Universidade de São Paulo, para obtenção do grau de Doutro em Direito, p - 256, março 1999

${ }^{10}$ BARBOSA MOREIRA, José Carlos. Efetividade do processo e técnica processual, in Temas de Direito Processual, Sexta série. " a) O processo deve dispor de instrumentos de tutela adequados, na medida do possível, a todos os direitos ( e outras posições jurídicas de vantagem) contemplados no ordenamento, quer resultem de expressa previsão normativa, que se possa inferir do sistema; b) esses instrumentos devem ser praticamente utilizáveis, ao menos em princípio, sejam quais forem os supostos titulares dos direitos (e das outras posições jurídicas de vantagem) de cuja preservação ou reintegração se cogita, inclusive quando indeterminado ou indeterminável o círculo dos eventuais sujeitos.; c) impedem assegurar condições propícias à exata e completa restituição dos fatos relevantes, a fim de que o convencimento do julgador corresponda, tanto quanto puder, à realidade; d) em toda a extensão da possibilidade prática, o resultado do processo há de ser tal que assegure à parte vitoriosa o gozo pleno da específica utilidade a que faz jus segundo o ordenamento; e) cumpre que se possa atingir semelhante resultado com o mínimo de dispêndio de tempo e energias."

${ }^{11}$ TEIXEIRA, Sálvio de Figueiredo. A reforma processual na perspectiva de uma nova justiça, in Reforma do Código de Processo Civil, p- 887. " na onda atual, a preocupação se volta para a efetividade dessa prestação, refletindo ideais de justiça e princípios fundamentais, tendo como idéias matrizes o acesso a uma ordem jurídica justa e a celeridade na solução do litígio, ao fundamento de que somente procedimentos ágeis e eficazes realizam a verdadeira finalidade do processo".

${ }^{12}$ Ide 3, p - 40, março 1999 . "Por ora, para finalizar este tópico, resumirei a definição de efetividade do processo na "maior correspondência possível entre resultados obtidos e os fins esperados de um dado sistema processual. E já adotando os nossos valores contemporâneos, e 


\section{DESENVOLVIMENTO TEÓRICO}

Os processualistas civilistas não discutem o valor-supra Justiça, estudado pelas Ciências Humanas e Jurídicas, mas precursores, como CAPPELLETTI e GARTH ${ }^{13}$, abordam a questão prática da acessibilidade ao Poder Judiciário, por vias processuais adequadas e céleres, sem prejudicar a estabilidade das relações jurídicas de uma sociedade. ${ }^{14}$

A proposta de Barbosa Moreira ${ }^{15}$ está na razoabilidade da estabilidade e celeridade, porém essa valoração depende daquele que opera os tipos de tutela jurisdicional e tipos de procedimentos ${ }^{16}$ - o juiz. São enfáticas as críticas ao recrutamento e à formação dos juízes, no Brasil, no tocante ao processo de Seleção, na Organização Judiciária e na ausência de posterior aprimoramento intelectual desses magistrados à mercê da realidade social brasileira ${ }^{17}$. As mudanças históricas e sociais reformularam o modelo da conduta positivista do juiz, em que era um mero espectador dos fatos postos em juízo e aplicador da lei o denominado "legalismo" ou o juiz como um ditador das normas processuais e "dono" absoluto do processo em que as partes figuravam apenas como súditos do julgador, o denominado "judicialismo". Eles propuseram uma a ampliação distorcida dos poderes do juiz ${ }^{18}$.

A evolução técnico e científica do subrramo do Direito Processual Civil, pautadas no certame de um Estado Democrático de Direito, estabeleceu um novo paradigma, o denominado "Juiz Diretor", em que o juiz tem a tarefa de presidir o processo e zelar pela seu saneamento, não podendo ficar alheio à realidade social, em busca da realização concreta da Justiça, posto que não é mais autoridade judiciária, mas servidor da comunidade ${ }^{19}$. A conduta do juiz deve ultrapassar os limites da simples observância da lei e motivação fundamentada das decisões judiciais. 0 importante é a posição participativa do juiz no contexto social, em face das diversidades culturais

utilizando-os como medida, a "efetividade do processo" quer dizer um processo que encontre um desejado equilíbrio entre justiça, acesso, estabilidade e celeridade, pois assim estaremos, o mais possível, realizando praticamente os fins esperados do nosso sistema processual."

${ }^{13}$ CAPPELLETTI, Mauro.

${ }^{14}$ Idem 5. " que muito se aproxima da idéias de justiça, é o acesso. Pouco ou nada adiantaria termos um processo que se aproxime da perfeição se o acesso formal a ele, ou aos meios que oferece, for inacessível à parte. Um processo ideal, mas para poucos. A ampla possibilidade de acesso às vias processuais é pressuposto inafastável de um sistema democrático, em que todos tenham as mesmas possibilidade".

${ }^{15}$ BARBOSA MOREIRA, José Carlos.

${ }^{16}$ YARSHEL, YARSHELL, Flávio Luiz, Tutela jurisdicional específica nas obrigações de declaração de vontade, São Paulo, Malheiros Editores, p- $38 / 55$ 1993.

${ }^{17}$ idem 9. P - 183, São Paulo, 1998. "Não basta que os magistrados conheçam com perfeição as leis tais como são escritas; seria necessário que conhecessem igualmente a sociedade em que essa leis devem viver.

O tradicional aforismo iura novit curia não tem nenhum valor prático se não se acompanhar deste outro: mores novit curia".

${ }^{18}$ MIRANDA, Vicente. Os poderes do Juiz no Processo Civil Brasileiro. Ed. Saraiva, 2ạ edição, São Paulo, 1993.

${ }^{19}$ NALINI, José Renato. Ética e Justiça. Editora Oliveira Mendes, p- 17, São Paulo, 1998. “ O juiz com esse comprometimento encontrará a alternativa hábil à concretização do justo, mediante flexibilização da rigidez esquemática do velho processo civil. A possibilidade de acordo se insere como contribuição eficaz à consecução da ordem jurídico/social juta, pois abreviará a tramitação da demanda, atingindo de logo o resultado somente alcançável a final. Com isso, está o Judiciário liberado para conhecer, apreciar e decidir outros conflitos, otimizando a sua capacidade produtiva." 
e econômicas dos cidadãos, e a recriação do sistema jurídico ${ }^{20}$ aberto ${ }^{21}$, por meio de uma atividade axiológica ${ }^{22}$, sempre voltada para a realidade social e visando à efetividade da tutela jurisdicional. ${ }^{23}$

Dentre os poderes estatais, o Poder Judiciário é o mais procurado, para a solução de conflitos, pelos "consumidores da Justiça", em virtude do contexto democrático. Esses cidadãos exigem, além do aparato estatal, também, a qualidade daqueles que os representam perante a sociedade. ${ }^{24}$

Os operadores do direito apresentam inúmeras propostas técnico-processuais, as quais asseguram o aprimoramento da prestação jurisdicional ${ }^{25}$, assim como as tendências do Novo Código de Processo Civil, as quais são reflexos da ampliação dos poderes do Juiz e dos órgãos jurisdicionais $^{26}$. Todavia, é fundamental reiterar-se que, mais do que as necessárias reformas processuais, o juiz deve estar atento à multiplicidade das demandas advindas do aumento da taxa populacional e da complexidade social, colaborando, dessa forma, com a regeengenharia do sistema processual e a mitigação da inoperatividade estatal. A ação do juiz deve estar pautada mais em "um razoável processo de ajuste interpretativo" do problema posto em juízo e a realidade do que em uma análise meramente dogmática ${ }^{27}$. Somente assim, haverá a satisfação da tutela pretendida - a efetividade da tutela jurisdicional.

O que pode fazer o juiz brasileiro para o aprimoramento da tutela jurisdicional? Como preleciona NALINI ${ }^{28}$, o juiz deve ousar refletir e ousar agir a insurreição ética do juiz.

\footnotetext{
${ }^{20}$ LARENZ,

${ }^{21}$ LUHMANN, Niklas. Editora Universidade de Bielefeld $\mathrm{p}$ - 163-188

${ }^{22}$ CAPPELLETTI, Mauro. Juízes Legisladores? Tradução de Carlos Alvaro de Oliveira, p - 33, Sergio Antonio Fabris Editor, 1999. “ Quem poderá negar agora que, para o direito, as decisões judiciárias constituem uma contribuição criativa, e não meramente descritiva? Não há outra forma de fazer de modo diverso, na medida em que raro é o caso de decisão que não pressuponha a escolha entre duas alternativas ao mesmo tempo admissíveis".

${ }^{23}$ MARTINS, Ives Gandra da Silva . Uma nova ética para o juiz. Coordenação José Renato Nalini. " O juiz e a economia. Reflexos da inflação na prestação jurisdicional", Revista dos Tribunais, p- 66, São Paulo, 1994. "Nada pode se transformar em prestação jurisdicional mais injusta do que aquela em que o magistrado se apega a conceitos formais do Direito, deixando de enfrentar as questões econômicas cujo reflexo nas relações jurídicas pode distorcer completamente as relações contratuais e jurídicas entre a sociedade e o Estado."

${ }^{24}$ Giuseppe Di Frederico. "Le qualificazioni professionali del Corpo Giudeiziario: Carenze attuali, possibili riforme e difficoltà di atuarle" in " Preparione Professionale Degli Avvocati e dei Margistrati: Discussione su una Ipotese di Reforma", Pádua, CEDAM - Casa Editrice Dott. Antonio Milani, 1987, p-4 e 6 apud NALINI, José Renato. Recrutamento e preparo de juízes. Revista do Tribunais, São Paulo, $1992, \mathrm{p}-17$.

${ }^{25}$ Como preleciona o Ministro Sálvio de Figueiredo Teixeira, invocando GIMENO SENDRA, para quem " a eficiência da Justiça estaria condicionada às garantias de a) pleno exercício do direito de ação e defesa; b) solução razoalvelmente rápida do litígio por órgão independente e mediante correta aplicação do direito; c) existência de medidas cautelares e executivas que possibilitem a tutela efetiva dos direitos e interesses legítimos".

${ }^{26}$ SOUZA, Carlos Aurélio Mota de Souza. Poderes éticos do juiz - A igualdade das partes e a repressão ao abuso no processo. Sergio Antonio Fabris, $\mathrm{p}$ - 77 à 145, Porto Alegre, 1987.

${ }^{27}$ MOURULLO, G. R apud GOMES. A dimensão da Magistratura no Estado Constitucionals e Democrático de Direito. Revista dos Tribunais, 1997, p-

152. "Aplicación judicial del derecho y lógica de la argumentación jurídica". Madrid: Civitas, p - 51 e ss., 1988.

${ }^{28}$ NALINI, José Renato. Ética e Justiça. Editora Oliveira Mendes, p- 17 e 265/269, São Paulo, 1998.
} 


\section{REFERÊNCIAS}

ARAGÃO, Moniz de. Efetividade do processo de execução, in O Processo de Execução - estudos em homenagem ao Professor Alcides Mendonça Lima. . p-3 /127.

AZEVEDO, Luiz Carlos de. TUCCI, José Rogério Cruz e. Lições de História do Processo Civil Romano, São Paulo, Ed. Saraiva , 1989.

BARBOSA MOREIRA, José Carlos. Efetividade do processo e técnica processual, in Temas de Direito Processual, Sexta série.

BENETI, Sidnei Agostinho e ANDREGHI, Fátima Nancy. O juiz na audiência. Revista de Processo, ano 1997.

CALAMANDREI, Piero. Eles, os Juízes vistos por um advogado. Tradução Eduardo Brandão, Martins Fontes, p- 159/160, São Paulo, 1998.

CAPPELLETTI, Mauro. Juízes Legisladores. Tradução de Carlos Alberto Álvaro de Oliveira. Sergio Antonio Fabris Editor, p-33 .Porto Alegre, 1999.

CAPPELLETTI, Mauro. Juízes Legisladores? Tradução de Carlos Alvaro de Oliveira, p - 33, Sergio Antonio Fabris Editor, 1999.

FERREIRA, Aurélio Buarque de Holanda. Dicionário Aurélio Básico da Língua Portuguesa. Editora Nova Fronteira, 1994/1995.

Giuseppe Di Frederico. "Le qualificazioni professionali del Corpo Giudeiziario: Carenze attuali, possibili riforme e difficoltà di atuarle" in "Preparione Professionale Degli Avvocati e dei Margistrati: Discussione su una Ipotese di Reforma", Pádua, CEDAM - Casa Editrice Dott. Antonio Milani, 1987, p- 4 e 6 apud NALINI, José Renato. Recrutamento e preparo de juízes. Revista do Tribunais, São Paulo, 1992, p- 17.

GOMES, Luiz Flávio. A dimensão da Magistratura no Estado Constitucionals e Democrático de Direito. Revista dos Tribunais, 1997, p-117.

LARENZ, Karl. Metodologia da Ciência do direito. Fundação Calouste Gulbenkian, 2a edição, Lisboa, 1989.

LUHMANN, Niklas. Editora Universidade de Bielefeld p - 163-188.

MARCACINI, Augusto Tavares Rosa. Estudo sobre a efetividade do processo. Tese apresentada ao Departamento de Direito Processual da Universidade de São Paulo, para obtenção do grau de Doutro em Direito, p-256, março 1999

MARINONI, Luiz Guilherme. A efetividade da do processo e Tutela de Urgência. Editora Sergio Antonio Fabris, p- 66, Porto Alegre, 1994. 
MARTINS, Ives Gandra da Silva . Uma nova ética para o juiz. Coordenação José Renato Nalini. “ O juiz e a economia. Reflexos da inflação na prestação jurisdicional”, Revista dos Tribunais, p- 66, São Paulo, 1994.

MIRANDA, Vicente. Os poderes do Juiz no Processo Civil Brasileiro. Ed. Saraiva, 2a edição, São Paulo, 1993.

MOURULLO, G. R apud GOMES. A dimensão da Magistratura no Estado Constitucionals $e$ Democrático de Direito. Revista dos Tribunais, 1997, p-152, "Aplicación judicial del derecho y lógica de la argumentación jurídica". Madrid: Civitas, p-51 e ss., 1988.

NALINI, José Renato. Ética e Justiça. Editora Oliveira Mendes, p- 17 e 265/269, São Paulo, 1998.

Uma nova ética para o juiz. Editora Revista dos Tribunais, p- 125, 152/153, São Paulo, ano 1994.

SPOTA, Alberto G. O juiz, o advogado e a formação do direito através da jurisprudência. Sergio Antonio Fabris Editor, 2a edição.

TEIXEIRA, Sálvio de Figueiredo Teixeira. O aprimoramento do processo civil como garantia da cidadania, in Revista da Ordem dos Advogados de Portugal, Lisboa, dezembro de 1994, p $811 / 812$.

A reforma processual na perspectiva de uma nova justiça, in Reforma do Código de Processo Civil, p- 887.

TUCCI, José Rogério Cruz e; AZEVEDO, Luiz Carlos de. Lições de História do Processo Civil Romano. Ed. Saraiva, p - 183, São Paulo, 1998.

YARSHELL, Luiz Flávio. Tutela jurisdicional específica nas obrigações de declaração de vontade, São Paulo, Malheiros Editores, p- 38/55, 1999.

\section{BASE DE DADOS:}

HOAISS, Koogan. Enciclopédia e Dicionário Digital. CDRom, Editora Delta, 1999. 